\title{
Spiritual Dimensions of Illness and Healing: The 4th Annual Medicine and Religion Conference
}

\author{
Daniel W. O'Neill ${ }^{a}$
}

${ }^{a}$ MD, MATSc, Assistant Professor of Family Medicine, University of Connecticut School of Medicine, USA

The Fourth Annual Conference on Medicine and Religion was held in Cambridge, MA, USA March 6-8, 2015. In western culture, there continues to be a divide between care for the body (by healthcare) and care for the soul (by religious communities). This dualism and reductionism may have led to clinical advances, but has resulted in increased mechanization of care, dehumanization of the patient experience, and isolation in the experi- ence of illness and dying. This conference was a forum for health care practitioners, scholars, religious leaders, chaplains, and students from various religious traditions, predominantly the monotheistic Abrahamic religions including Christianity, to address these issues and interact toward a more integrated approach to health care.

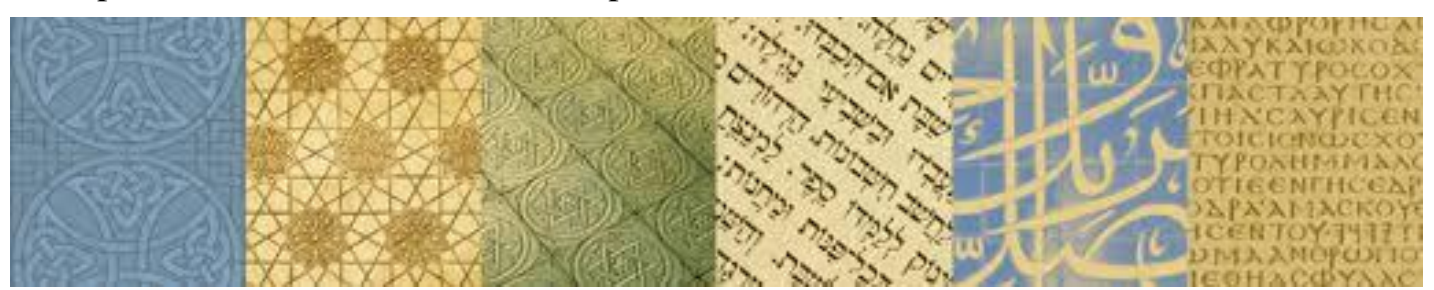

In the first plenary session, a case study was presented of an African-American woman diagnosed with advanced cervical cancer who attributed her disease to her sins and challenged the objectivity of her "non-religious" treating physician. ${ }^{1}$ The multidisciplinary panel reflected on an approach to integrating her belief systems into her clinical care. Harold Koenig, MD (Duke University's Center for Spirituality, Theology and Health) discussed the two paradigms at work - the clinician's and the patient's, and the need to communicate with her in her own Christian paradigm, to embrace prayer for healing as synergistic with the chemotherapy and radiation, and to affirm her understanding of her disease viewed as the consequence of her sins and her desire to be forgiven and recover for her future ministry purposes. Rev. Gloria White-Hammond, MD (Bethel AME Church, Boston) encouraged building trust, involving her faith community, eval-

uating her understanding of disease, sin, penance, and atonement, as well as what God was saying to her in her circumstances. Linda Barnes, $\mathrm{PhD}$ (Medical Anthropologist, Boston University) highlighted the socio-economic framework needed to consider clinical care among the working poor, the racial divide and possible fatalism associated with it, the tension of authority between medical/scientific reality and spiritual truths, with a need to develop "meaning-centered explanations" including a paradigm of ultimate healing. Heather Curtis, MA, ThD (Historian, Tufts University) related the long Christian tradition of suffering as a spiritual experience, exemplified by Jesus Christ. Curtis identified the Protestant view of illness and pain helpful for the purification of the flesh and the greater spiritual purposes in suffering and that she retained a priority for spiritual growth over her freedom from disease. In her paradigm, even the healthy (i.e., her physi- 
cian) needed to prioritize relationship with God. George Handzo, MDiv (HealthCare Chaplaincy Network of New York City) noted the absence of a critical spiritual history in the clinical encounter, the delay in involving a "spiritual care professional" (i.e., chaplain) from the beginning, and addressing the affective as well as the cognitive aspects of care. This may take the form of "spiritual care teams" as practiced with Adventist Health Care ${ }^{2}$ and allowing space and presence in order for the suffering to create meaning in the face of illness. ${ }^{3}$

In the second plenary session entitled In what sense is illness a spiritual and/or religious experience?, Rabbi Saul Berman, JD (Yeshiva University), representing a Jewish perspective, proposed that spirituality in the face of illness gives an awareness of the presence of God, highlights the ultimate set of values and virtues over which humans govern their lives, and gives opportunity to experience the effects of sin and, in healing or comfort, the experience of divine love - the way things ought to be. Ahsan M. Arozullah, MD, MPH (Astellas Pharma \& Darul Qasim), representing a Muslim perspective, highlighted the divine will in cause of both illness and cure, but that the cause and effect for particular cases remains indefinable. Margaret Mohrmann, MD, PhD (University of Virginia), representing a Christian perspective, spoke of Jesus Christ as revealing the necessity of death, and the possibility of life, and the need to ask and account for how the afflicted person understands their world with cultural humility (more than just cultural competency), and by providing a narrative of hope and "ordered love" (Augustine) that challenges the existing order of despair.

In the third plenary session by the same panel entitled How should particular spiritual and religious needs of patients be addressed and by whom?, Rabbi Berman highlighted the universal call to do no harm, the scripture-informed duty to rescue those nearby, seeing them through their faith community which shapes who they are and recog- nizing the imago Dei in them. This requires all health workers to ask them about their spiritual needs and then listen. Dr. Arozullah proposed divisions of labor - only those trained and qualified to address spiritual needs. Professor Mohrmann cautioned that we can easily draw conclusions or categorize before allowing the person space to open up regarding spiritual matters. She noted the need to be sensitive to power and authority differentials, to be open to silence in the patient encounter, to understand other traditions, and practice loving chastisement when appropriate.

In the keynote address entitled Cares, Taking Care and Caregiving: The Vital Nexus between Religion and Medicine, Arthur Kleinman, MD, MA (Harvard University) spoke of the time-compressed, technology-driven contemporary health systems that have depersonalized and diminished the value of shared responsibility of basic care-giving in communities. What is needed is affirmation of the person (not just the disease or problem) and moral solidarity as a critical component - what he describes as "presence" which has roots in religion. This calls for clinical pastoral education. He recognized that global health care has unquestionable religious roots with social networks and moral experience formative for health, with trans-local aspirations and essential strategies for enduring illness and improving care. As a non-Theist, he noted the increase in atheism in the West and a "robust plurality" in culture, but he recognized religion as a key source for revitalizing caregiving. He notes the examples of James Grant of UNICEF and Hafden Maller of WHO as well as Clara Barton who drew from their Christian missionary backgrounds as "crucial motivation," but recognized the hesitancy on the part of secular society to see religion as a global asset in the health domain. Though current health systems are "systematically disabling students from the human side of care," his solution was a caregiving movement from the bottom up. 
In the third and final plenary, the same panel of three addressed the question: What is at stake and what is experienced, spiritually, among those who care for patients? Reflecting on several case presentations, Rabbi Berman noted that we need to move from personal awareness of spirituality to the level of holiness - to the actualization of values in the caregiver's daily life. This is accomplished by a deeper understanding of the character of God found in Exodus 34:6-7, of which justice is central to transform the health of our society. Dr. Arozullah pointed out the pitfalls of misplaced intentions (pleasing God, pleasing the patient, or getting the best outcome), the "God complex," or the mistake of serving the means or the ends instead of the person. Prof. Mohrmann extoled the value of endurance, grace, and generosity, even on the worst of days - that we will receive what we need when doing what we must. The dehumanization of medicine is a human decision, and to dehumanize is to desacralize and miss the opportunity to re-wright meaning by engaging in the life narrative of the afflicted, sharing our own narratives, and proclaiming anew realities which reveal that a spiritual community is a healing community.

There were many papers and posters presented on the interface of religion and health care, including one by Ashley Moyse, $\mathrm{PhD}$, defining life from a Christian perspective: bounded by and inclusive of death and made hopeful by practicing availability and fidelity in caregiving through joy and sorrow and treating the afflicted as a subject, not an object - embodying valid hope toward a reconciled future. Elizabeth Marshall, MD, MAT discussed Job and the value of lament as a means to hope and healing, and a paper on the life of renown vascular surgeon Alexis Carrel's discovery that the mystical state of union with Christ surpassed cognition and reason, so that at the end of his life he could write that he felt like a "small child before God." There were many other topics such as the importance of recovering a transcendent dimension of health care and a "hidden curriculum" in training which provides mentors who model compassion and empathy.

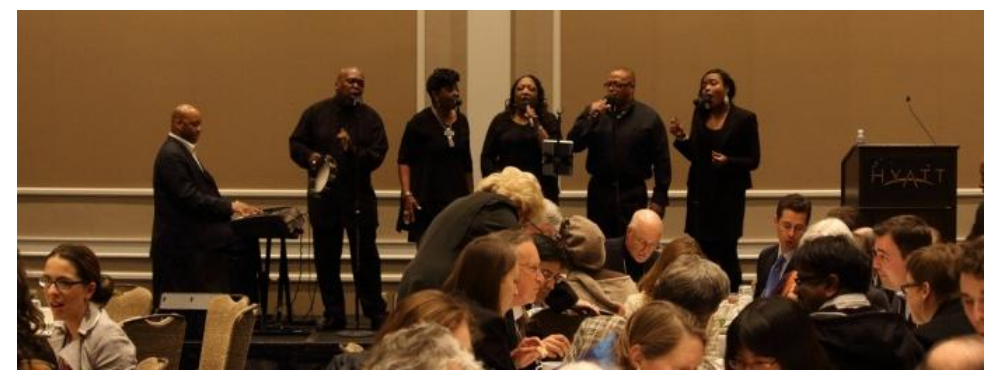

Though the conference was quite diverse in its various Theistic views and traditions, the Christian perspective was well-represented, and it created space for dialogue with other faiths. There was a gallery of art work related to Christian contexts of health care, and a group of African-American gospel singers created an uplifting backdrop during the banquet. There was not a strong application for global health contexts, but many of the principles shared have valuable application for international health care, education, and community develop- ment, some of which have been shared in this brief report.

\section{References}

1. An Interdisciplinary Case Discussion on "I was Bleeding for My Sins" [Available at http://www.medicineandreligion.com/aninterdisciplinary-case-discussion-on-i-was-bleedingfor-my-sins.html ]

2. Koenig H G. The spiritual care team: Enabling the practice of whole person medicine, Religions 2014, 5(4), 1161-1174. http://dx.doi.org/10.3390/rel5041161 
events: Measurement tools and approaches. Journal of

3. Park C L, \& George L S (2013). Assessing meanPositive Psychology, 8, 483-504. ing and meaning making in the context of stressful life http://dx.doi.org/10.1080/17439760.2013.830762

Competing Interests: None declared.

Correspondence: Daniel W. O'Neill, University of Connecticut School of Medicine, dwoneill@cjgh.org

Cite this article as: O'Neill, DW. Spiritual Dimensions of Illness and Healing: The 4th Annual Medicine and Religion Conference. Christian Journal for Global Health (May 2015), 2(1): 80-83.

(C) O'Neill, DW. This is an open-access article distributed under the terms of the Creative Commons Attribution License, which permits unrestricted use, distribution, and reproduction in any medium, provided the original author and source are properly cited. To view a copy of the license, visit http://creativecommons.org/licenses/by/3.0/

wWw.cjgh.org

May 2015. Christian Journal for Global Health 2(1): 80-83. 